University of Nebraska - Lincoln

DigitalCommons@University of Nebraska - Lincoln

Educational Psychology Papers and

Publications

Educational Psychology, Department of

September 1994

\title{
Consulting With Teachers About Girls and Boys
}

Susan M. Sheridan

University of Nebraska-Lincoln, ssheridan2@unl.edu

Mary Henning-Stout

Lewis \& Clark College

Follow this and additional works at: https://digitalcommons.unl.edu/edpsychpapers

Part of the Educational Psychology Commons

Sheridan, Susan M. and Henning-Stout, Mary, "Consulting With Teachers About Girls and Boys" (1994). Educational Psychology Papers and Publications. 23.

https://digitalcommons.unl.edu/edpsychpapers/23

This Article is brought to you for free and open access by the Educational Psychology, Department of at DigitalCommons@University of Nebraska - Lincoln. It has been accepted for inclusion in Educational Psychology Papers and Publications by an authorized administrator of DigitalCommons@University of Nebraska - Lincoln. 


\title{
Consulting With Teachers About Girls and Boys
}

\author{
Susan M. Sheridan \\ University of Utah \\ Mary Henning-Stout \\ Lewis \& Clark College
}

The purpose of this article is to clarify issues of gender relevant to the practice of consultation with classroom teachers. Social psychological and educational considerations are reviewed as grounding for gender-fair educational practices which consultation can help to bring about. Finally, the specific implications of this theoretical and empirical grounding for the practice of organizational, behavioral, and mental health consultation are explored.

There is no escaping it. Consultation, whenever it is undertaken, occurs in a cultural context that has gender as one of its most salient categories (Bem, 1985). Specific to school consultation, there are gender considerations in teachers' interactions with students (American Association of University Women [AAUW], 1992; Eccles \& Blumenfeld, 1985; M. Sadker, D. Sadker, \& Klein, 1991); in students' approaches to learning (Belenky, Clinchy, Goldberger, \& Tarule, 1986; Gilligan, Lyons, \& Hammer, 1990); in curricular content (Meece, 1987; M. Sadker et al., 1991); in school structure and personnel assignment (Schmuck, 1987); and, drawing inferences from research on communication, in the ways adults involved in education talk with each other (Spender, 1987; Tannen, 1990).

In this article, we explore the implications of these gender considerations for the practice of consultation with classroom teachers. We begin by setting our inquiry within the larger frame of research on gender as

Requests for reprints should be sent to Susan M. Sheridan, Department of Educational Psychology, University of Utah, 327 Milton Bennion Hall, Salt Lake City, UT 84112. 
a cultural construct and, therefore, a factor in the socialization of children and adults in educational settings. We continue our discussion by focusing more directly on ways in which gender expectations may restrict consultation. Finally, we demonstrate the application of a gender-fair orientation to the practice of organizational, behavioral, and mental health consultation in schools.

\section{THE CONSTRUCT OF GENDER}

Bem $(1981,1985)$ suggested that the emphasis on gender in our culture is an option. Jacklin (1989) and Maccoby and Jacklin (1974) demonstrated that there is far more overlap than difference in the characteristics of females and males. At the same time, there are important gender differences in social experiences and consequent behaviors that have significant implications for educators (Gilligan et al., 1990; Jacklin, 1989). The manner in which these similarities and differences are attended to influences the academic and social development of girls and boys in schools.

Historically, gender differences have been interpreted in ways that benefit males over females. The persistence of this valuation is familiar and not difficult to catalogue. For example, Charlotte Perkins Gilman (1979) wrote the novel Herland in 1915 as a reflection on the extent to which American culture was structured around biological sex. Gilman suggested that women's capacity to bear children, a capacity not shared by men, stood as the irrevocable difference between the genders. American culture of her day dealt with this difference by instituting social practices ensuring male domination, sex-based division of labor, and socialized (not innate) passivity on the part of most women (Martin, 1985).

Beliefs about the passive domesticity of women and the public agency of men have been passed on in expectations for the behaviors of children. These expectations are illustrated in widespread beliefs about male students having greater aptitude in science and math-beliefs that persist in spite of evidence showing no significant difference in the math and science achievement of female and male students (Feingold, 1988; Marsh, 1989). Expectations may be changing as evident in recent findings reflecting girls' stated preferences for math and science as favored academic subjects (Archer \& McDonald, 1991). These same findings, however, indicated that girls applied stereotypes when listing the academic courses female students should take (e.g., home economics was mentioned most frequently; Archer \& McDonald, 1991). The strength of these stereotypes, which support expectations about 
which children will take on the responsibilities for caring for children and families, are equally potent. Ironically, as women have gained more access to the public world, the status of "feminine" activities has seemed to falter. Even the AAUW (1992) emphasizes the importance of encouraging girls in math and science without taking a similarly strong stance advocating the importance of teaching and raising the status of nurturing and relational skills.

The tendency to view these more "feminine" skills as less important than more "masculine" foci of math and science persists in the structuring of education. When behaviors associated with women are devalued and behaviors associated with men are acclaimed, children naturally respond to the contingencies by modeling the behaviors of higher value. Fundamental learning theory can be applied to understanding the effects of these cultural values. If female children receive systematically less reinforcement or are discouraged as they demonstrate culturally valued behaviors, they will be in the confusing position of observing the behavior-reinforcement link while receiving powerful information that they are somehow not to have access to the cycle. If girls' attempts to produce the behaviors reinforced in boys are punished by being overlooked or actively discouraged, girls will be less likely to develop those behaviors (skills) and will come to think of themselves as incapable in those valued areas of academic and social activity. The emergence of learned helplessness in girls as a result of these contingencies has been empirically demonstrated (Dweck, Goetz, \& Strauss, 1980; Steward \& Corbin, 1988).

Gender-biased cultural contingencies present a sobering set of conditions. At the same time, these conditions are easily overlooked in the day-to-day life of schooling (Henning-Stout \& Conoley, 1992). In spite of greater social awareness, federal law (Title IX), and increasing numbers of women working outside the home, the evidence for gender inequity in schools is growing (AAUW, 1992; Oakes, 1990; M. Sadker et al., 1991). Research on gender issues in schools has highlighted inequities in relation to teacher-student interactions, enculturated expectancies, and curricular and instructional content. Such research can inform school consultation practice if consultants attempt to confront the potential influence of gender-biased attitudes on students' social, emotional, and academic development.

\section{Teachers' Interactions With Students}

Until the 1970s, gender-related research and criticism of schools focused on the difficulties experienced by male students. This research emphasized concern for male achievement and saw these boys as "victims of a 
hostile feminine school environment" (M. Sadker et al., 1991, p. 294). Over the past 2 decades, however, empirical evidence has grown to indicate the cost to female students who more closely meet the expectations of classroom teachers (e.g., Fennema \& Peterson, 1978; Meece, 1987; Redfield \& Rousseau, 1981). These findings have indicated a "detrimental 'trade-off' between teachers and docile students; whereas females received higher grades for conforming to classroom norms, males received more active instruction in their more assertive and central classroom role" (M. Sadker et al., 1991, p. 295).

As early as preschool, teachers interact in a different way with girls than with boys. Stipek and Sanborn (1985) found preschool teachers interacting with girls and handicapped children of both sexes in ways that encouraged passive learning, docile conduct, and lack of initiative and perseverance. Preschool teachers have been observed to encourage imitation, rule learning, help seeking, and nurturing in the play of girls while encouraging boys' exploration, problem solving, creativity, and independence (Huston, 1983). Huston and Carpenter's (1985) study of the interactions of preschool teachers with their students indicated that both girls and boys were supported in activities structured by rules and clear teacher expectations (e.g., completing a specific craft activity, taking responsibility for watering the plants in the classroom). At the same time, boys were allowed and expected to participate in significantly more unstructured play than girls.

In elementary schools, teachers have been found to interact more often with male than female students (M. Sadker \& D. Sadker, 1984). Boys receive more acknowledgment, approval, criticism, corrective comments, encouragement, and praise than do girls. In science classrooms, boys are asked more questions requiring abstract reasoning, whereas girls are more likely to be asked questions of fact (Morse \& Handley, 1985). As a result, boys were requested to rehearse their abstract thinking skills publicly, whereas girls were required to recite facts requiring less complex and independent thought. Morse and Handley also found that the discrepancy in asking questions of boys and girls increased as students moved from seventh to eighth grade.

In elementary and middle schools, boys have been found to call out eight times more often than girls (M. Sadker, D. Sadker, \& Thomas, 1981). Teachers tended to respond to boys calling out by accepting or overlooking the verbalization and continuing the class. When, on occasion, girls called out in class, teachers were most likely to correct the behavior by saying something like, "In this class, we raise our hands" (M. Sadker et al., 1991, p. 298). Similar studies across the school years indicate that, as students move through the higher grades and into postsecondary classes, in-class interaction decreases and the student 
contributions that do occur are likely to come from a few male students (M. Sadker \& D. Sadker, 1986; Tobin, 1988).

The decrease in interaction at these higher levels of education may decrease the educational benefit to some female students who learn best in the context of collaboration and relationship (Belenky et al., 1986; Gilligan et al., 1990). These women gain less from academic content when it is presented in traditional, depersonalized, and individualistic ways.

\section{Gender Differences in Learning}

The seeming mismatch between higher level education and the ways in which some female students learn best highlights the problem of instructional effectiveness. In the enterprise of educating, it is important to know if there are systematic differences in groups of people that can be accommodated with specific instructional approaches (in effect known as aptitude-treatment interaction; Chronbach \& Snow, 1977). However, the nature of such interactions based on gender has been difficult to discern.

When considering cognitive abilities by gender, there has been consistent agreement that there is more variance within gender groupings than between them (Feingold, 1988; Jacklin, 1989; Maccoby \& Jacklin, 1974). The modest superiority of females in verbal ability has disappeared over the past 15 years (Jacklin, 1989; Marsh, 1989), and the slightly higher spatial ability demonstrated by male students is declining (Feingold, 1988; Linn \& Hyde, 1989; Marsh, 1989). "The absence of substantive differences in ability by gender suggests that instruction should be developed to respond to the learning needs of the individual and that planning according to gender alone is ill-advised" (Oakes, 1990, p. 204). This suggestion seems especially pertinent in the areas traditionally thought to be the "natural" strengths of girls (language arts) or boys (math and science; Archer \& McDonald, 1991).

On the other hand, the findings of Belenky et al. (1986) and Gilligan et al. (1990) should not be overlooked and seem to indicate that, in the context of gender socialization (i.e., girls more likely to be socialized toward relationship and boys more likely to be socialized toward independence), some girls may learn more in classrooms where collaboration is encouraged. Fennema and Peterson (1985) found that male students benefit academically from competitive classroom climates to a greater extent than female students. Boys have also been found to benefit from participation in small groups. In such settings, boys were more likely to receive help from the group when requested and female group members were observed to be quick to respond to male students' requests (Wilkinson, Lindow, \& Chiang, 1985). All of these findings have implications for instruction. Because the research in this area is 
new, it remains to be seen if the benefits of more collaborative learning accrue solely for female students or if students of both genders gain from such a pedagogy. As collaborative learning is explored and developed, the already socialized tendencies toward dominance and submission in male and female students must be considered.

Special education. As mentioned previously, differences in learning seem to be greater within gender and would predict similar distributions in demonstrated ability across female and male students. The contrast between this prediction and the representation of girls and boys in special education bears consideration. For example, Oakland and Stern (1989) investigated the aptitude and achievement levels of girls and boys and found no gender effect. This finding led the authors to question the vastly higher probability of boys being identified as underachievers in schools. The best illustration of the tendency to identify boys as needing special help is found in the significantly greater number of boys classified as learning disabled in our current special education system (Office of Civil Rights, 1987). In a study of schoolwide perceptions of girls' and boys' social behaviors, teachers' descriptions of students' behaviors did not match their referrals of students for special education services (Henning-Stout, 1993). Although teachers perceived no differences in the frequency and intensity of the acceptable and troubling behaviors of girls and boys, boys were referred far more frequently than girls for special help. Teachers tend to rate boys' disturbing behaviors as more problematic than girls' troubling behaviors, which may result in a higher rate of boys being referred for special educational placements (Schlosser \& Algozzine, 1979). Furthermore, the atmosphere of elementary classrooms has often been characterized as "feminine," with expectations for compliance and docility the norm. However, boys tend to be reinforced for externalizing, aggressive, and independent behaviors that may not be adaptive in the classroom. Thus, reinforced "masculine" behaviors, when they are perceived as disturbing to teachers, may result in a disproportionate number of boys being referred out of the mainstream and into special education classes. These findings seem to indicate that, although there is increased research attention to the extent to which girls are overlooked or discounted in classroom practice (M. Sadker et al., 1991), the learning by boys continues to be of greatest concern to the educational system.

\section{Curricular Content}

In the past 2 decades, published educational curricula have shown vast improvement in equalizing the numbers of female and male characters 
in textbooks (M. Sadker et al., 1991). This improvement in numbers of characters has not been accompanied by equalization in the portrayal of those characters in a broad range of behaviors. For example, Purcell and Stewart (1990) analyzed the content of 62 elementary readers and found equal representation of females and males but a greater tendency to portray females as helplessly dependent on males. Of greater concern are recent studies of texts in history (Davis, Ponder, Burlabaw, GarzaLudeck, \& Moss, 1986) and geography (Mayer, 1990) which indicate that women's contributions continue to be minimized or overlooked entirely.

The less formal school curriculum, composed of books read aloud in class, acquired for classroom libraries, and available in larger school libraries, is equally subject to the gender-biased themes evident in formal school curricula. Although there is evidence that award-winning children's books are inclusive, gender-fair, and culturally pluralistic portrayals, the evidence for the rest of children's literature is less positive (Christian-Smith, 1989; White, 1986). In addition, M. Sadker and her colleagues (1991) noted that teachers tend to choose books they enjoyed as children and, "because most teachers themselves grew up with older books representing highly traditional gender roles, the influence of these more sexist books remains pervasive" (p. 277). Thus, the print media available for use in classrooms are, for the most part, perpetuating gender stereotypes.

\section{School Structure and Personnel Assignment}

The stereotypes in curricula seem to mirror the staffing practices within education. The teaching profession historically has been comprised of women, with only a few holding administrative roles. As of 1988, only $28.8 \%$ of the elementary principals, $11.6 \%$ of the secondary principles, and $3.7 \%$ of the superintendents in the American public school system were women (Jones \& Montenegro, 1988; M. Sadker et al., 1991). These statistics indicate the relatively less powerful influence of women in school organizations and inevitably set a model for what students can expect as they move into adult careers. The tendency of schools to support the movement of male teachers into degree and certification programs preparing them for educational administration posts explains the underrepresentation of women (M. Sadker et al., 1991) and stands as a key point for organizational development.

\section{Gender Considerations in Communication}

Whenever professionals in educational settings work with one another, the social construct of gender is an immediately salient variable. Tannen's (1990) psycholinguistic research into differences in the ways 
women and men use language to communicate their thoughts, ideas, and needs illustrates the immediacy of gender as a variable in professional interaction. Women talk with women differently than men talk with men and differently than women and men talk with each other. Women tend to speak out publicly less often than men, and men are more likely to interrupt women than women are to interrupt men (West \& Zimmerman, 1985). In one study of conversations among pairs of university professors, women were found to be perceived by men and to perceive themselves as dominating a conversation when they spoke $35 \%$ of the time. Conversations in which women spoke more than $44 \%$ of the time ended in unresolved conflict with the man blaming the woman for the impasse in communication (Spender, 1987).

A study of mixed-sex conversation among adults revealed that women tend to take responsibility for keeping their male partners engaged by asking questions, making eye contact, and allowing interruption - that is, anticipating and meeting men's conversational needs (Fishman, 1983). These findings are consistent with the characteristics of female-male interaction among students in small-group work described previously (Wilkinson et al., 1985). The extent to which these dynamics are in place in the work of professionals in schools remains an empirical question worth considering. Questions of the socialized gender-bias underlying failed communication can be helpful in removing blocks to communication and, by extension, enhancing responsiveness to students' educational needs.

\section{BARRIERS TO SUCCESSFUL CONSULTATION}

Based on the previous discussion, four fundamental barriers to genderfair consultation can be identified. First, differential expectations on the part of the teacher or consultant for girls' and boys' academic performances in particular content areas may interfere with academic progress. Second, related barriers are the differential expectations for and responses to girls' and boys' social behaviors. Third, there may be unequal participation in the problem-solving process due to an unacknowledged gender-based power differential between a teacher and consultant (e.g., with a female teacher and a male consultant). A final barrier to successful consultation is the lack of teacher or consultant awareness of gender-biased beliefs and practices.

Identifying barriers is only an initial step. If consultants are to recognize and overcome these barriers, practical options are needed. Techniques for building gender awareness into consultation practice can 
be discerned by considering the models of consultation as vehicles for both applying and influencing gender-fair practice. Such techniques are considered next.

\section{IMPLICATIONS FOR CONSULTATION}

There are several practices in which school consultants can engage to address gender inequities. These practices can be discussed at a number of levels, including the school's organizational culture, the behaviors of teachers and students, and implicit beliefs of school patrons.

\section{Organization/System Level}

Organizational evaluation. To promote systemic changes in sexstereotyped behaviors within schools, systematic assessment and evaluation of organizational norms and practices is necessary. Organizational characteristics such as staff composition, curriculum, communication patterns, gender representation within special education classrooms, sex-role attitudes, and power distributions can be investigated by an organizational consultant. Consultants might begin by reviewing school records, attending meetings, conducting observations, collecting questionnaire data, and interviewing school staff and patrons (i.e., administrators, teachers, support staff, students, and parents) with the intent of evaluating organizational variables such as those just presented. Based on the outcomes of this investigation, the consultant can provide feedback to school staff, help to change inequities demonstrated across genders, promote flexible alliances within the school, and address institutional resistance to changes in the traditional roles and practices of pupils and school staff.

Curriculum and instruction. Much of the curriculum in today's schools promotes sex-stereotypical beliefs and practices. As previously mentioned, children's school books often portray male characters as adventuresome and successful. Male characters are more likely to be engaged in challenging professions such as medicine and law (Meece, 1987; M. Sadker et al., 1991). In addition, the arrangement of classroom space and materials often reinforces separateness and differences, with little emphasis on shared strengths and abilities (Lee \& Gropper, 1974). For example, the physical layout in preschool classrooms traditionally provides for "feminine" activities such as playing house and caring for dolls. "Masculine" objects such as tools, trucks, and building blocks are also provided their own distinct space. These curricular and instruc- 
tional practices must be examined and challenged-a process in which a consultant could assist.

Regarding curricular inequities, a consultant can help school organizations examine the "hidden curriculum" within educational practices. For example, classroom space and materials should be integrated to diminish the somewhat arbitrary demarcations used to support traditional associations with male and female. Likewise, subtle stereotypes conveyed in school textbooks can be studied overtly in social studies or literature lessons. For example, the differential portrayal of women as nurturant and supportive, rather than industrious and independent, can be examined. Such discussions can be followed with lessons on prominent women such as Amelia Earhart and Madame Curie. Students can thus be encouraged to scrutinize sex role culture by examining and questioning it (Lee \& Gropper, 1974) and by recognizing women's competence, importance, and contributions to science and history.

Inequitable practices. It is common for schools to perpetuate differential expectations for students depending on their gender. For example, boys are differentially reinforced for excelling in math and science, whereas girls are encouraged in the development of relational skills (AAUW, 1992; Henning-Stout \& Conoley, 1992; M. Sadker et al., 1991). However, given the lack of any conclusive genetic explanations (FaustoSterling, 1985; Jacklin, 1989), gender differences in achievement are best explained with social reinforcement theory (Eccles \& Jacobs, 1986; Hyde \& Linn, 1986, 1988). According to Oakes (1990), "gender-related differences may be caused less by some unique needs of women . . . than by the fact that they typically have less access to positive factors that favor high achievement and continued participation in general" (p. 204). Traditionally, boys have received vocational counseling gearing them toward "masculine" careers or careers with high status. Girls, on the other hand, generally have been stereotyped in roles that were less important, easier, safer, and related to their stereotypic task of nurturer and homemaker (Meece, 1987; Thomas \& Stewart, 1971). Although this trend appears to be changing in the past decade, it is still incumbent upon school personnel to challenge such limited views and promote a wide spectrum of career choices for all students, regardless of gender. Consultants can facilitate this process by challenging stereotyped curricula; helping teachers and counselors make a range of options available to all students; and modeling open, nonstereotyped attitudes regarding career choices.

Staff training and in-service. Perhaps the greatest opportunity for a consultant to influence organizational practices is through formalized 
staff development. In-service programs can be implemented to effectively increase the knowledge base of all school staff (M. Sadker \& D. Sadker, 1982). The myths and realities of gender differences can be reviewed, methods for decreasing inequitable practices in the school and classroom can be shared, and opportunities for students to engage in nontraditional experiences within the school can be generated.

Given the extent to which sex-role stereotypes are ingrained in the school culture and the resistance of organizations toward change, consultants would be wise to expect that change in attitudes, beliefs, and behaviors will be slow. The schoolwide organization represents only one level at which efforts for change should be directed. The overt behaviors and implicit beliefs of teachers and school staff should also be addressed.

\section{Teacher Behaviors}

Given their amount of exposure to students, individual teachers (perhaps more than any other individuals within the school) possess tremendous potential for affecting students' sex-role stereotypes, expectations, and behaviors. Thus, consultants interested in having an impact on sex roles within a school and the manner in which they reflect or promote stereotypical practices would do well to direct consultation efforts toward the overt actions of significant adults in a child's school experience (i.e., the teachers).

Efforts directed at altering behaviors of individual teachers are warranted on several accounts. Earlier, we described several normative practices within educational environments that result in inequitable school experiences for boys and girls. When such practices are observed, or when outcomes of educational curricula reflect differential achievement by boys and girls, classroom teachers may benefit from knowledge and skill development directed at minimizing the academic and social gaps between boys and girls.

The skill and knowledge of individual teachers can be influenced within behavioral consultation relationships. Behavioral consultation in schools is broadly defined as an indirect model of service delivery in which a consultant works with a consultee to promote change and improve the educational experiences of students. The general goals of behavioral consultation include remediating existing problems and preventing future similar problems by increasing the knowledge and skills of consultees (Bergan \& Kratochwill, 1990; Kratochwill \& Bergan, 1990).

Knowledge base of teachers. Prior to expecting any behavioral changes, it may be appropriate to recognize the need for teachers and 
other school staff to extend their knowledge bases regarding the truths and myths of gender differences. For example, teachers who accept the enculturated belief that boys are better than girls in mathematic and scientific endeavors are likely to be caught in circular reasoning, which presumes biological or genetic predispositions for which there is no strong evidence (Jacklin, 1989; Lee \& Gropper, 1974). In fact, any cognitive differences between the sexes appear to be influenced more by cultural and social expectations than by hereditary differences (FaustoSterling, 1985; Hyde, 1981; Hyde \& Linn, 1988; Linn \& Hyde, 1989).

There are several mechanisms that can be utilized to enhance the knowledge base of teachers. Within the context of consultation, individual teachers can gain information from consultants regarding genderfair practice. A prudent approach for consultants may be to highlight the similarities and competencies of girls and boys and not the differences between genders.

Gender differences are often noted in grades and standardized achievement scores (Eccles, 1987; Eccles \& Blumenfeld, 1985). In these cases, a consultant may approach individual teachers or groups of teachers informally and inquire about student performances. Direct observations within the classroom may provide both the consultant and teacher (who may be unaware of potentially biased practices) with insights about relevant actions and reactions. In-services with larger groups of educators also can be conducted with the intent of disseminating information on sex-role stereotypes and their effects to a larger audience.

Direct teacher training. In addition to extending knowledge, consultation should also be directed at improving specific skills of teachers interacting with their students in a gender-fair manner. Some teachers will be capable of using newly learned information and translating it into educational practices within the classroom. Other teachers will require direct training to modify gender-stereotypic attitudes and behaviors.

The teacher-training research suggests a number of procedures that are effective in delivering educative services to teachers. Didactic instruction, modeling, role playing, cueing, and feedback have all been used effectively by various researchers (Allen \& Forman, 1984; Anderson \& Kratochwill, 1988; Bernstein, 1982; Jones \& Eimers, 1975; M. Sadker \& D. Sadker, 1982; Van Houten \& Sullivan, 1975). Findings suggest that didactic instruction should be used in combination with other training methods (e.g., role playing and feedback). In other words, simply providing information is not adequate to change behaviors. Consultants concerned with expanding teachers' skills and practices should also spend time observing in classrooms and providing 
feedback regarding student behaviors that teachers may not notice, or regarding differential teacher practices toward girls and boys. They may also help teachers review topics, select materials, and set up instructional centers to empower teachers with a repertoire of gender-fair alternatives from which to operate.

Social and operant procedures. Along with direct efforts at improving the knowledge and skill bases of teachers, some research has shown that consultant modeling of verbal behaviors can affect consultee behaviors (Cleven \& Gutkin, 1988). Social learning theories would suggest that modeling and observation may produce powerful learning effects in consultees. For example, a consultants' modeling of cross-sex expectancies, gender-fair practices, and nonstereotypic attitudes can promote similar behaviors in teachers. Consultants can also demonstrate positive reinforcement and establish programs to promote crosssex interests of students (Liben \& Bigler, 1987). It may be particularly effective to model such practices by providing group interventions or co-teaching appropriate curricula within the classroom itself. This will also provide both consultants with opportunities to observe teachers interacting with students and teachers with feedback on their interactions with boys and girls.

In order to be effective models, it is imperative that consultants recognize and analyze their own gender beliefs, attitudes, and actions prior to engaging in consultation. Critical self-evaluation of implicit gender perceptions and explicit behavioral practices is a necessary prerequisite for all consultants striving to provide gender-fair services.

Operant-based procedures provide yet another method of affecting differential expectations of and behaviors toward girls and boys in schools. Specifically, social praise and acknowledgment to teachers who engage in nonstereotypic educational practices can be a sincere means of support and reinforcement. Likewise, positive recognition of teachers' efforts to promote cross-sex interaction, provide equal access to educational resources regardless of gender, and acknowledge individual social and learning strengths of all students may serve to increase similar gender-fair practices in the future. Such reinforcement and recognition from consultants (male or female) must be sincere and meaningful without implicit sexist connotations.

Prereferral consultation. In an attempt to circumvent differential placement into special education programs, prereferral consultation services may be appropriate. Specific objectives of these services should be to monitor and decrease gender-biased referrals and placements by intervening within the regular classroom. Most states now have a 
prereferral system in place, in which several attempts at remediation must be documented prior to referral for testing. As part of this process, consultants should carefully examine the nature and severity of the presenting problems to uncover any potential gender biases. For example, does an individual teacher repeatedly refer girls or boys for testing? How does this teacher instruct and interact with students (i.e., boys and girls) in the classroom? What is the nature of the tasks given, and how does the teacher respond to inquiries and problems of students?

Through behavioral observations and nonthreatening interview procedures, a range of information pertinent to gender differences can be ascertained. Consultant efforts can then be directed toward identifying the actual problem, analyzing ecological conditions surrounding its occurrence, brainstorming alternative solutions, developing action plans to remediate the problem, and establishing an appropriate evaluation methodology.

Student programs promoting nonstereotypic practices. A necessary component of consultation services is a strategic action plan for addressing problems directly. If differential educational practices lead to differential student performance, programs aimed directly at students may be appropriate. For example, students should be encouraged and reinforced to engage in nonstereotypic experiences. Girls may demonstrate interest in science or math and should be positively reinforced for competing in science fairs or math competitions. At the same time, the status and importance of traditional feminine activities (e.g., caregiver, nurturer) can be emphasized. Boys may have a desire to learn traditionally feminine skills, and should be rewarded for enrolling in courses such as home economics or cooking. Active attempts to encourage such cross-sex activities should be made on a schoolwide level (e.g., through announcements and student newsletters) and also at the individual teacher level (e.g., through consultation and in-services).

\section{Addressing Attitudes and Beliefs}

There appears to be an interrelationship between human behavior and beliefs. Thus, attempts to change overt behaviors of individuals within school settings may likely alter their beliefs and attitudes regarding certain groups (e.g., boys and girls). However, regardless of the amount of energy consultants exert, not all efforts at changing teachers' behaviors will be successful at modifying pervasive attitudes regarding gender differences. Thus, efforts aimed at modification of teachers' personal attitudes and beliefs represent the third and most personal level at 
which consultants can work. These consultant interventions may be conceptualized from a mental health consultation perspective (Caplan, 1970; Meyers, Parsons, \& Martin, 1979).

In mental health consultation, the primary focus is on helping teachers identify and resolve current work-related difficulties and enabling them to handle similar and future problems independently (Caplan, 1970). According to Caplan, a potential source of consultee difficulty may be his or her lack of objectivity (i.e., personal and subjective consultee factors that influence one's ability to perform in an entirely competent manner).

Indeed, gender-related issues may be among the subjective factors that enter into consideration when teachers analyze the actions of a particular child. For example, two young boys may get into a loud argument about the rules of kickball during recess. The argument may include threats and name-calling, yet this interchange is likely to be minimized and regarded as "boys being boys." However, an observer viewing the same interaction occurring between two girls may consider such vocal and "aggressive" behaviors as atypical and problematic. The exchange between boys may be discounted by teachers and other school staff, whereas the same exchange between girls may result in a request for intervention.

In mental health consultation, consultee attitudes and affect are considered central variables. That is, the personal issues of the consultee are recognized as potential barriers to effective practice. These attitudes and personal issues can take the form of gender stereotypical beliefs about differential abilities or the appropriateness of behaviors of boys and girls. Thus, consultation efforts should be directed at changing the subjective judgments, stereotypical attitudes, or other personal factors of the consultee in order to provide a more gender-fair learning environment. Some ways that this can be accomplished are through the use of direct and indirect confrontation and reframing.

Direct confrontation. When operant or social learning interventions (such as contingent reinforcement or consultant modeling) are ineffective at changing the overt actions of consultees in their interactions with students, direct confrontation may be appropriate. For example, a consultant may make several classroom observations to determine the manner in which a teacher responds differentially to boys and girls. The data obtained from these observations may provide the impetus for addressing stereotypical practices of teachers. Confrontations may take the form of direct statements such as "I noticed that you responded to $75 \%$ of the boys whose hands were raised, whereas you responded to 
only $35 \%$ of girls who tried to elicit your help." Or, they may be more indirect in nature, such as "You seem to spend significantly more time interacting with and helping boys as compared to girls. I wonder why?"

The purpose of confrontational statements is to help teachers recognize their practices more explicitly, with the intent of addressing underlying attitudes and beliefs that may be directing some of their actions. Thus, consultation should not stop at the point of confrontation but must be followed with constructive dialogue. The dialogue should center on inaccurate beliefs of teachers (e.g., girls are less capable in mathematics; boys are cognitively superior in hard sciences) and may involve some teacher education regarding myths and realities of gender differences. Likewise, the dialogue should address specific and pragmatic suggestions on how to modify stereotypical practices to increase effectiveness.

Extreme care must be taken to ensure that a trusting consultation relationship is well-established prior to attempting a potentially intrusive action such as confrontation. Indeed, the potential for resistance is great if the teacher feels threatened or patronized by a consultant's actions or "expertise." To minimize teacher resistance, it is important to develop and maintain collaborative relationships with teachers; demonstrate respect and positive regard for teachers' knowledge, contributions, and difficulties; listen in a truly nonjudgmental manner; and reinforce efforts sincerely through moral support and encouragement (Zins, Curtis, Graden, \& Ponti, 1988).

Reframing. Reframing is an important tool of a consultant and should be used to encourage consultees to perceive situations and actions in alternative ways. Reframing allows a consultant to take one behavior, attitude, or viewpoint and place it into another "frame" by encouraging alternative perspectives of the same situation. It allows a consultant to approach a consultee's stereotypic beliefs and attitudes subtly, and it provides opportunities for a consultant to recognize and acknowledge consultee statements and modify them in an attempt to alter perceptions.

Two examples may illustrate the skill of reframing more concretely. First, a teacher may make gender-related attributions about a child's academic or social abilities, such as "Patty, like most girls, is really struggling with pre-algebra." This type of dispositional statement is both circular and nonfunctional. Because Patty's difficulty is attributed to her status as a girl, the problem becomes unsolvable. By reframing the problem to consider curricular or other environmental factors contributing to Patty's difficulties, a teacher and consultant become empowered to achieve control and hence solve the problem. Thus, the same statement can be reframed as "Patty seems to have mastered the concrete skills of 
grouping and borrowing but is still grappling with more abstract concepts. How can we make these concepts more concrete?"

As a second example, a preschool teacher may state that she prefers to keep the boys' "rough-and-tumble" toys (such as climbing blocks) separate from the girls' activities (such as play kitchens) to minimize confusion in the classroom. Such a statement can be reframed into one of concern for order and safety rather than sex differentiation, such as "I can see that you are concerned that your classroom is a safe place for girls and boys, regardless of the toys with which they prefer to play."

\section{SUMMARY}

In this article, we attempted to delineate issues of and provide recommendations for consulting with teachers about gender stereotypes. Social psychological considerations were highlighted, and school influences on children's gender identity and sex-role stereotypes were addressed. Finally, specific implications and recommendations for consultation were raised from organizational, behavioral, and mental health perspectives. In general, any or all of these approaches can be effective for influencing gender-related practices within schools.

In addition to the recommendations made throughout the article, some suggestions to help consultants recognize the potential influence they have in this area are listed next. These suggestions represent only a few possible actions consultants might take; the possibilities are limited only by one's imagination.

1. Consultants can help teachers recognize when their conceptualizations of boys and girls appear to be unfounded, gender-based biases. This can help teachers recognize diversity within and between groups of students and support individual strengths and talents.

2. Consultants can strive to invoke a school philosophy that considers children as individuals rather than representatives of different genders.

3. Consultants can help teachers recognize that boys and girls are more alike than different and that there is more variation within than between genders. Furthermore, educators can be assisted in recognizing that both boys and girls have educationally relevant strengths and that these strengths should be utilized and not squelched.

4. Attention should be paid to matching the content of interventions with the developmental level of students for which they are intended. Likewise, explicit attempts to change teachers' and students' behaviors, and not simply attitudes or cognitions, should be considered (Katz, 1986).

5. Consultants can ensure that all children have equal access to 
educational resources. These include the resources of teacher skills, expectations, and values, as well as physical facilities and programmatic offerings of the school. To attain such fair educational practices, an organizational assessment and consultation aimed at program development may be necessary. This will help more fully develop the strengths of each child, male and female.

6. Consultants can influence the encouragement of and response to children expressing interest in "nontraditional" careers. This can be accomplished through modeling and positive reinforcement of students exploring various vocational interests. Likewise, consultants can assist guidance counselors, administrators, and teachers in broadening rather than limiting career alternatives for girls and boys.

7. Consultants must review critically their own potential gender biases. Such careful reflection may provide consultants with a clearer vision, which can in turn lead to quicker recognition of and response to inequities based on gender or any other characteristic.

8. Finally, if we hope to attain long-term change, we must examine carefully and strive to alter entire socialization experiences and social support systems. As suggested by Liben and Bigler (1987), "the effect of repeated stereotypic modeling and reinforcements during the individual's entire life history would be difficult to extinguish by a short, highly restricted set of experiences" (p. 98). Continuous consultation efforts directed toward modifying socialization practices and the context of social supports in schools can reinforce this long-term process.

\section{REFERENCES}

Allen, C. T., \& Forman, S. G. (1984). Efficacy of methods of training teachers in behavior modification. School Psychology Review, 13, 26-32.

American Association of University Women. (1992). How schools shortchange girls. Washington, DC: AAUW Educational Foundation.

Anderson, T. K., \& Kratochwill, T. R. (1988). Dissemination of behavioral procedures in the schools: Issues in training. In J. C. Witt, S. N. Elliott, \& F. M. Gresham (Eds.), Handbook of behavior therapy in education (pp. 217-244). New York: Plenum.

Archer, J., \& McDonald, M. (1991). Gender roles and school subjects in adolescent girls. Educational Researcher, 33, 55-64.

Belenky, M. F., Clinchy, B. M., Goldberger, N. R., \& Tarule, J. M. (1986). Women's ways of knowing. New York: Basic.

Bem, S. L. (1981). Gender schema theory: A cognitive account of sex typing. Psychological Review, 88, 354-364.

Bem, S. L. (1985). Androgyny and gender schema theory: A conceptual and empirical integration. In T. B. Sonderegger (Ed.), Nebraska symposium on motivation: Psychology and gender (Vol. 32, pp. 180-226). Lincoln: University of Nebraska Press.

Bergan, J. R., \& Kratochwill, T. R. (1990). Behavioral consultation and therapy. New York: Plenum. 
Bernstein, G. S. (1982). Training behavior change agents: A conceptual review. Behavior Therapy, 13, 1-23.

Caplan, G. (1970). The theory and practice of mental health consultation. New York: Basic.

Christian-Smith, L. (1989). New directions for curriculum content. Contemporary Education, 61, 11-14.

Chronbach, L. J., \& Snow, R. E. (1977). Aptitudes and instructional methods: A handbook for research on interactions. New York: Irvington.

Cleven, C. A., \& Gutkin, T. B. (1988). Cognitive modeling of consultation processes: A means for improving consultee's problem definition skills. Journal of School Psychology, 26, 379-389.

Davis, O. L., Ponder, G., Burlabaw, L., Garza-Lubeck, M., \& Moss, A. (1986). A review of U.S. history textbooks. The Education Digest, 52, 50-53.

Dweck, C. S., Goetz, T. E., \& Strauss, N. L. (1980). Sex differences in learned helplessness: IV. An experimental and naturalistic study of failure generalization and its mediators. Journal of Personality and Social Psychology, 38, 441-452.

Eccles, J. S. (1987). Gender roles and achievement patterns: An expectancy value perspective. In J. M. Reinesch, L. A. Rosenblum, \& S. A. Sanders (Eds.), Masculinity/femininity: Basic perspectives (pp. 240-280). New York: Oxford University Press.

Eccles, J., \& Blumenfeld, P. (1985). Classroom experiences and student gender: Are there differences and do they matter? In L. C. Wilkinson \& C. B. Marrett (Eds.), Gender influences in classroom interaction (pp. 79-114). Orlando, FL: Academic.

Eccles, J. S., \& Jacobs, J. E. (1986). Social forces shape math attitudes and performance. Signs, 11, 367-389.

Fausto-Sterling, A. (1985). Myths of gender: Biological theories about women and men. New York: Basic.

Feingold, A. (1988). Cognitive gender differences are disappearing. American Psychologist, 43, 95-103.

Fennema, E., \& Peterson, P. L. (1978). Effective teaching for girls and boys: The same or different? In D. C. Berliner \& B. V. Rosenshine (Eds.), Talks to teachers (pp. 111-125). New York: Random House.

Fennema, E., \& Peterson, P. L. (1985). Autonomous learning behavior: A possible explanation of gender-related differences in mathematics. In L. C. Wilkinson \& C. B. Marrett (Eds.), Gender-related differences in classroom interaction (pp. 17-35). New York: Academic.

Fishman, P. M. (1983). Interaction: The work women do. In B. Thorne, C. Kramarae, \& N. Henley (Eds.), Language, gender, and society (pp. 89-101). Rowley, MA: Newbury House.

Gilligan, C., Lyons, N. P., \& Hanmer, T. J. (Eds.). (1990). Making connections: The relational worlds of adolescent girls at Emma Willard School. Cambridge, MA: Harvard University Press.

Gilman, C. P. (1979). Herland. New York: Pantheon.

Henning-Stout, M. (1993). The relationship between teachers' perceptions of girls' and boys' behaviors and referral for special education. Special Services in the Schools, 7, 91-105.

Henning-Stout, M., \& Conoley, J. C. (1992). Gender: A subtle influence in the culture of the school. In F. J. Medway \& T. P. Cafferty (Eds.), School psychology: A social psychological perspective (pp. 113-135). Hillsdale, NJ: Lawrence Erlbaum Associates, Inc.

Huston, A. C. (1983). Sex typing. In D. H. Mussen (Ed.), Handbook of child psychology. Vol. 4: Socialization, personality, and social behavior (4th ed., pp. 387-467). New York: Wiley.

Huston, A. C., \& Carpenter, J. (1985). Gender differences in preschool classrooms: The effects of sex-typed activity choices. In L. C. Wilkinson \& C. B. Marrett (Eds.), Gender differences in classroom interactions (pp. 143-165). New York: Academic. 
Hyde, J. S. (1981). How large are cognitive gender differences? A meta-analysis using $w^{2}$ and $d$. American Psychologist, 36, 892-901.

Hyde, J. S., \& Linn, M. C. (1986). The psychology of gender: Advances through meta-analysis. Baltimore: Johns Hopkins University Press.

Hyde, J. S., \& Linn, M. C. (1988). Are there sex differences in verbal abilities?: A meta-analysis. Psychological Bulletin, 104, 53-69.

Jacklin, C. N. (1989). Female and male: Issues of gender. American Psychologist, 44, 127-133.

Jones, E. H., \& Eimers, R. C. (1975). Role playing to train elementary teachers to use classroom management "skill package." Journal of Applied Behavior Analysis, 8, 421-433.

Jones, E. H., \& Montenegro, X. P. (1988). Women and minorities in school administration. Arlington, VA: American Association of School Administrators.

Katz, P. A. (1986). Modification of children's gender-stereotyped behavior: General issues and research considerations. Sex Roles, 14, 591-601.

Kratochwill, T. R., \& Bergan, J. R. (1990). Behavioral consultation in applied settings: An individual guide. New York: Plenum.

Lee, P., \& Gropper, N. (1974). Sex role, culture, and educational practice. Harvard Educational Review, 44, 369-410.

Liben, L. S., \& Bigler, R. S. (1987). Reformulating children's gender schemata. In L. S. Liben \& M. L. Signorella (Eds.), Children's gender schemata (pp. 89-105). San Francisco: Jossey-Bass.

Linn, M. C., \& Hyde, J. S. (1989). Gender, mathematics, and science. Educational Researcher, 18, 17-19, 22-27.

Maccoby, E. E., \& Jacklin, C. N. (1974). The psychology of sex differences. Stanford, CA: Stanford University Press.

Marsh, H. W. (1989). Sex differences in the development of verbal and mathematics constructs: The high school and beyond study. American Educational Research Journal, 26, 191-225.

Martin, J. R. (1985). Reclaiming a conversation: The ideal of the educated woman. New Haven, CT: Yale University Press.

Mayer, T. (1990). Consensus and invisibility: The representation of women in human geography textbooks. The Professional Geographer, 41, 397-409.

Meece, J. L. (1987). The influence of gender of school experiences on the development of gender schemata. In L. S. Lisben \& M. L. Signorella (Eds.), Children's gender schemata (pp. 57-73). San Francisco: Jossey-Bass.

Meyers, J., Parsons, D., \& Martin, R. (1979). Mental health consultation in schools. San Francisco: Jossey-Bass.

Morse, L. W., \& Handley, H. M. (1985). Listening to adolescents: Gender differences in science classroom interactions. In L. C. Wilkinson \& C. B. Marrett (Eds.), Gender influences in classroom interaction (pp. 37-56). New York: Academic.

Oakes, J. (1990). Opportunities, achievement, and choice: Women and minority students in science and mathematics. In E. Cazden (Ed.), Review of research in education (pp. 153-222). Washington, DC: American Educational Research Association.

Oakland, T., \& Stern, W. (1989). Variables associated with reading and math achievement among a heterogeneous group of students. Joumal of School Psychology, 27, 127-140.

Office of Civil Rights. (1987). 1986 elementary and secondary school civil rights survey. (Contract No. 300-86-0062). Washington, DC: Department of Education.

Purcell, P., \& Stewart, L. (1990). Dick and Jane in 1989. Sex Roles, 22, 177-185.

Redfield, D., \& Rousseau, E. (1981). A meta-analysis of experimental research on teacher questioning behavior. Review of Educational Research, 51, 237-247.

Sadker, M., \& Sadker, D. (1982). Year 3: Final report promoting effectiveness in classroom instruction. Washington, DC: National Institute of Education. 
Sadker, M., \& Sadker, D. (1984). Promoting effectiveness in classroom instruction (Report No. 143). Washington, DC: National Institute of Education, Department of Education. (ERIC Document Reproduction Service No. ED 257 819)

Sadker, M., \& Sadker, D. (1986). Sexism in the classroom: From grade school to graduate school. Phi Delta Kappan, 69, 512.

Sadker, M., Sadker, D., \& Klein, S. (1991). The issue of gender in elementary and secondary education. In G. Grant (Ed.), Review of research in education (Vol. 17, pp. 269-334). Washington, DC: American Educational Research Association.

Sadker, M., Sadker, D., \& Thomas, D. (1981). Sex equity and special education. The Pointer, 26, 30-36.

Schlosser, L., \& Algozzine, B. (1979). The disturbing child: He or she? Alberta Journal of Educational Research, 25, 30-36.

Schmuck, P. (Ed.). (1987). Women educators: Employees of schools in western countries. Albany: State University of New York Press.

Spender, D. (1987). The writing or the sex. New York: Pergamon.

Stewart, M. J., \& Corbin, C. B. (1988). Feedback dependence among low confidence preadolescent boys and girls. Research Quarterly for Exercise and Sport, 59, 160-164.

Stipek, D. J., \& Sanborn, M. E. (1985). Teachers' task-related interactions with handicapped and nonhandicapped preschool children. Merrill-Palmer Quarterly, 31, 285-300.

Tannen, D. (1990). You just don't understand: Women and men in conversation. New York: Ballantine.

Thomas, A. H., \& Stewart, N. R. (1971). Counselor response to female clients with disparate and conforming career goals. Journal of Counseling Psychology, 18, 352-357.

Tobin, K. (1988). Target student involvement in high school science. International Jourmal of Science Education, 10, 317-330.

Van Houten, R., \& Sullivan, K. (1975). Effects of an audio cueing system on the rate of teacher praise. Journal of Applied Behavior Analysis, 8, 197-202.

West, C., \& Zimmerman, D. H. (1985). Gender language and discourse. In T. A. VanDijk (Ed.), Handbook of discourse analysis. Vol. 4: Discourse analysis in society (pp. 103-124). London: Academic.

White, H. (1986). Damsels in distress: Dependency themes in fiction for children and adolescents. Adolescence, 21, 251-256.

Wilkinson, L. C., Lindow, J., \& Chiang, C. P. (1985). Sex differences and sex segregation in students' small-group communication. In L. C. Wilkinson \& C. B. Marrett (Eds.), Gender influences in classroom interaction (pp. 185-207). New York: Academic.

Zins, J. E., Curtis, M. J., Graden, J. L., \& Ponti, C. R. (1988). Helping students succeed in the regular classroom. San Francisco: Jossey-Bass. 